\title{
CITRA DAN HARAPAN TERHADAP KAWASAN KESAWAN DI KOTA MEDAN
}

\author{
Meta Vaniessa Tampubolon ${ }^{1, *}$, Hanson E. Kusuma ${ }^{2}$, Cahyo Septianto Hutomo ${ }^{3}$ \\ ${ }^{1,3}$ Program Studi Magister Arsitektur, SAPPK, Institut Teknologi Bandung \\ Jl. Ganesha No. 10 Bandung, 40132 \\ ${ }^{2}$ Kelompok Keahlian Perancangan Arsitektur, SAPPK, Institut Teknologi Bandung \\ Jl. Ganesha No. 10 Bandung, 40132 \\ *E-mail: metatampubolon07@gmail.com
}

\section{Diterima: 15 Oktober 2019}

\begin{abstract}
ABSTRAK. Masyarakat yang tinggal di suatu kawasan akan mengalami kualitas fisik dan non fisik yang ada di kawasan tersebut secara langsung. Pengalaman sehari-hari dalam suatu kawasan akan menciptakan citra dan harapan terhadap kawasan tersebut. Kawasan bersejarah dianggap penting sebagai karakter dan nilai citra suatu daerah. Kawasan Kesawan merupakan kawasan bersejarah yang berada di Kota Medan. Penelitian ini bertujuan untuk mengungkap citra dan harapan Kawasan Kesawan menurut penduduk Kota Medan. Penelitian ini menggunakan metode kualitatif yang bersifat eksploratif. Data dikumpulkan dengan membagikan kuesioner daring yang berisi pertanyaan terbuka. Kemudian didapatkan data teks yang berisi persepsi dan pemikiran masyarakat tentang citra dan harapan terhadap Kawasan Kesawan. Data tersebut dianalisis dengan analisis isi. Dari hasil analisis, terungkap bahwa citra Kawasan Kesawan yang dominan di mata penduduk Kota Medan adalah memiliki nilai sejarah tetapi tidak terawat. Terungkap pula bahwa mempertahankan bangunan lama dan tetap menjadikan Kawasan Kesawan sebagai kawasan bersejarah adalah harapan penduduk Kota Medan yang dominan.
\end{abstract}

Kata kunci: analisis isi, citra, harapan, Kawasan Kesawan, nilai sejarah

ABSTRACT. Communities living in an area will experience physical and non-physical qualities in the area directly. Daily experience in an area will create an image and expectations for the area. Historical areas are considered as important as the character and image value of an area. Kesawan area is a historical area in the city of Medan. This study aims to reveal the image and expectations of the Kesawan area, according to the residents of Medan City. This study used qualitative methods that are explorative. The data were collected by distributing an online questionnaire containing open-ended questions. The text data provided the perceptions and thoughts of the community about the image and expectations of the Kesawan area. The data were analyzed by content analysis. From the results of the study, it was revealed that the dominant image of the Kesawan area is the historical value but not maintained. It was also revealed that keeping the old building and still making the Kesawan area as a historic area are the expectations of the residents of Medan City.

Keywords: content analysis, expectations, historical value, image, Kesawan area

\section{PENDAHULUAN}

Kawasan bersejarah merupakan lokasi atau daerah yang memiliki warna atau ciri khas yang dapat memberi keunikan dan identitas untuk kawasan tersebut (Ichwan, 2004). Berdasarkan UU No.11 tahun 2010 (Pemerintah Indonesia, 2010) kawasan atau bangunan disebut bersejarah apabila bangunan, benda atau strukturnya memenuhi kriteria: berusia 50 tahun atau lebih dengan menjadi bagian dari pola hidup sebelumnya, dan memiliki jejak peninggalan sejarah yang dapat disampaikan untuk kebutuhan pendidikan, kebudayaan juga agama. Dalam undang-undang yang sama juga disebutkan bahwa keberadaan kawasan bersejarah penting untuk menjadi karakter dan nilai citra suatu daerah.

Medan merupakan kota terbesar ke-tiga di Indonesia setelah Jakarta dan Surabaya, berusia 428 tahun, serta memiliki banyak sejarah dan peninggalan pada masa kolonial, salah satunya Kawasan Kesawan. Kawasan tersebut ditetapkan menjadi kawasan cagar budaya di Kota Medan tahun 2011 dalam Perda No.13 tentang RTRW kota Medan. Namun, disebutkan dalam koran harian Analisa tanggal 10 Juni 2014, terdapat ironi mengenai Kawasan Kesawan sebagai kawasan bersejarah peninggalan Kesultanan Deli di Kota Medan terbengkalai dan citranya mulai hilang. 
Beberapa peneliti telah berusaha untuk memahami Kawasan Kesawan. Harisdani \& Lubis (2004) meneliti Kawasan Kesawan dengan fokus penelitian tentang kepraktisan bangunan ruko yang berdampak pada mengaburkan identitas Kawasan Kesawan. Tegar (2017) menyatakan adanya citra yang muncul dari sisi bangunan yang ada di Kawasan Kesawan dan citra ini memunculkan kriteria-kriteria desain untuk memperbaiki citra kawasan. Baik Harisdani \& Lubis (2004) ataupun Tegar (2017) fokus pada persoalan kualitas visual citra Kawasan Kesawan. Penelitian dilakukan dengan metode penelitian kualitatif dan metode pengumpulan data observasi dan arsip.

Hadinugroho (2017) dan Fatimah (2017) melakukan penelitian tentang cara merevitalisasi dan mengembalikan citra Kawasan Kesawan. Penelitian Hardinugroho (2017), mengidentifikasi potensi lokasi Kawasan Kesawan dengan fungsi pendukung di sekitarnya. Fatimah (2017), menyusun rencana lanskap untuk pelestarian sejarah maupun bangunan di Kawasan Kesawan. Penelitian ini menghasilkan kriteria untuk menaikkan kualitas kawasan sebagai lanskap sejarah.

Pada Kawasan Kesawan terdapat bangunan bersejarah yang masih ada hingga saat ini yaitu, Mansion. Penelitian oleh Christyawaty (2011), membahas mengenai tata ruang dan elemen penyusun pada Mansion Tjong A Fie. Hutauruk \& Rambe (2017), melakukan penelitian untuk konservasi yang dapat dilakukan pada bangunan sejarah ini.

Penelitian-penelitian yang telah dilakukan di Kawasan Kesawan fokus pada persoalan kualitas visual citra dari bangunan bersejarah (Harisdani \& Lubis, 2004; Tegar, 2017), konfigurasi ruang bangunan bersejarah (Christyawaty, 2011), dan konservasi dan revitalisasi bangunan dan Kawasan Kesawan (Hardinugroho, 2017; Fatimah, 2017; Hutauruk dan Rambe, 2017). Penelitian-penelitian tersebut cenderung menggunakan pendekatan kualitatif dengan metode pengumpulan data observasi dan arsip.

Temuan penelitian mungkin sangat dipengaruhi oleh interpretasi dari peneliti. Penelitian ini mencoba untuk melengkapi pengetahuan dari penelitian yang telah disebutkan di atas.

\section{METODE PENELITIAN}

Penelitian ini menggunakan pendekatan kualitatif grounded theory (Cresswell, 2008) yang bersifat eksploratif (Groat \& Wang, 2002). Penelitian eksploratif ini bertujuan untuk mendapatkan data berupa informasi mengenai citra dan harapan untuk Kawasan Kesawan dari perspektif dan persepsi responden yang merupakan perwakilan dari masyarakat Kota Medan.

\section{Metode Pengumpulan Data}

Cara pengumpulan data yang digunakan untuk penelitian ini berupa kuesioner daring. Kuesioner dibagikan secara bebas (snowballnon-random-sampling), lewat jejaring sosial maupun lewat kenalan pribadi dengan batasan kepada orang yang pernah tinggal atau yang tinggal di Kota Medan. Jumlah responden yang diperoleh sebanyak 174 orang dengan usia 18-54 tahun. Jumlah responden laki-laki sebanyak 99 orang $(56,9 \%)$ dan perempuan sebanyak 75 orang $(43,1 \%)$. Pekerjaan dari responden terbagi menjadi empat, yaitu bekerja dalam bidang arsitektur/perencanaan wilayah dan kota sebanyak 30 orang $(17,3 \%)$, bekerja di luar bidang arsitektur/perencanaan wilayah dan kota sebanyak 78 orang $(44,8 \%)$, mahasiswa dalam bidang arsitektur/ perencanaan wilayah kota sebanyak 28 orang $(16,1 \%)$, dan mahasiswa di luar bidang arsitektur/ perencanaan wilayah dan kota sebanyak 38 orang $(21,8 \%)$.

Pertanyaan tentang citra dan harapan terhadap Kawasan Kesawan berupa pertanyaan terbuka. Pertanyaan terbuka seperti: "Bagaimanakah kesan anda terhadap Kawasan Kesawan? Jelaskan selengkap mungkin."

Responden dapat menuliskan dan menjelaskan jawaban apapun sesuai dengan yang mereka rasakan ataupun pikirkan.

\section{Metode Analisis Data}

Data teks yang terkumpul dari pertanyaan terbuka, dianalisis dengan analisis isi. Analisis isi menggunakan tiga tahapan koding: open coding, axial coding, dan selective coding. Open coding bertujuan mengidentifikasi kata kunci dan mengkategorikan kata-kata kunci yang mirip. Axial coding dilakukan untuk melihat hubungan antar kategori dengan membandingkan kemiripan dan perbedaannya. Selective coding merupakan tahapan 
menyusun model hipotesis berdasarkan penafsiran terhadap hasil axial coding.

\section{ANALISIS DATA}

Pada tahap pertama analisis data teks yang terkumpul dari responden, dilakukan open coding. Contoh identifikasi kata kunci pada open coding dari komentar responden mengenai citra Kawasan Kesawan dapat dilihat sebagai berikut.

\begin{abstract}
"Sangat padat penduduk, sumpek, macet, daerah wisata tapi tidak terawat." (Masyarakat, bekerja di luar bidang arsitektur/perencanaan wilayah kota)
\end{abstract}

"Standard. Karena tidak terawat, sehingga kesan kolonial hilang." (Masyarakat, bekerja dalam bidang arsitektur/perencanaan wilayah kota)

Berdasarkan deskripsi di atas, dapat ditemukan beberapa kata kunci dari citra Kawasan Kesawan yaitu Padat yang mewakili frasa "padat penduduk, sumpek"; Macet dari frasa "macet"; Tempat wisata dari frasa "daerah wisata"; Tidak terawat mewakili frasa "tidak terawat"; Biasa aja mewakili frasa "standard"; Kolonial hilang mewakili frasa "kolonial hilang".

Open coding dari harapan responden terhadap Kawasan Kesawan dapat dilihat pada kutipan hasil kuesioner berikut.

"Harapan saya, Kawasan Kesawan agar lebih diperhatikan lagi, diperbaiki namun tidak merombak bangunan aslinya agar tetap mempertahankan nilai sejarahnya, arsitektur bangunannya, yg menunjukkan kalau ini merupakan salah satu kota tua di Kota Medan." (Masyarakat, bekerja di luar bidang arsitektur/perencanaan wilayah kota)

"Harapannya seharusnya bangunannya dari bentuk fasade tetap dijaga, adanya pembatasan akses kendaraan sehingga tidak semrawut, misalnya seperti kota tua di Singapura." (Masyarakat, bekerja dalam bidang arsitektur/perencanaan wilayah kota)

Berdasarkan deskripsi responden mengenai harapan terhadap Kawasan Kesawan ditemukan kata kunci yaitu Lebih diperhatikan mewakili frasa "lebih diperhatikan"; Diperbaiki mewakili frasa "diperbaiki"; Tidak merubah bangunan asli mewakili frasa "tidak merombak bangunan aslinya, bentuk fasade tetap dijaga"; Menjadi aset bersejarah mewakili frasa "tetap mempertahankan nilai sejarahnya, arsitektur bangunannya"; Menjadi icon kota tua Medan mewakili frasa "merupakan salah satu kota tua di Kota Medan"; Membatasi akses kendaraan mewakili frasa "adanya pembatasan akses kendaraan"; Tidak berantakan mewakili frasa "tidak semrawut"; Studi dengan kota tua yang berhasil mewakili frasa "seperti kota tua di Singapura".

Setelah dilakukan open coding selanjutnya kata-kata kunci dikelompokkan (axial coding) sehingga ditemukan kategori 15 kategori untuk citra dan 17 kategori untuk harapan terhadap Kawasan Kesawan. Kemudian kategorikategori dianalisis secara distribusi. Tahap axial coding dapat dilihat pada tabel 1 dan tabel 2.

Tabel 1. Contoh Axial Coding citra Kawasan Kesawan

\begin{tabular}{lll}
\hline No. & \multicolumn{1}{c}{ Kategori } & \multicolumn{1}{c}{ Kata Kunci } \\
\hline \multirow{2}{*}{1} & Kurang Nyaman & $\frac{\text { Gelap }}{\text { Menyeramkan }}$ \\
\cline { 3 - 3 } & $\frac{\text { Sepi }}{\text { Tidak Ramah Difabel }}$ \\
\hline 2 & Macet & $\frac{\text { Padat }}{\text { Ramai }}$ \\
& & Sempit \\
\hline
\end{tabular}

Tabel 2. Contoh Axial Coding Harapan terhadap Kawasan Kesawan

\begin{tabular}{|c|c|c|}
\hline No. & Kategori & Kata Kunci \\
\hline \multirow{5}{*}{1} & & Diperbaiki \\
\hline & & Dipertahankan \\
\hline & Mempertahankan & Tidak dirusak atau \\
\hline & Bangunan Lama & dihancurkan \\
\hline & & $\begin{array}{l}\text { Tidak merubah bangunan } \\
\text { lama }\end{array}$ \\
\hline \multirow{5}{*}{2} & \multirow{5}{*}{$\begin{array}{l}\text { Menata Ulang } \\
\text { Kawasan }\end{array}$} & Lebih luas \\
\hline & & Memberi sentuhan modern \\
\hline & & $\begin{array}{l}\text { Studi dengan kota tua yang } \\
\text { berhasil }\end{array}$ \\
\hline & & Tidak berantakan \\
\hline & & Zona yang jelas \\
\hline
\end{tabular}

Kategori yang ditemukan kemudian dianalisis baik dari citra maupun harapan untuk menemukan jawaban yang paling dominan. Hasil analisis distribusi citra dapat dilihat pada Grafik 1. Citra yang paling tercermin mengenai kawasan Kesawan bagi masyarakat adalah Memiliki nilai historikal sebesar $75(21,6 \%)$, kemudian Tidak terawat sebesar 36(10,4\%). Citra yang paling tidak tergambar mengenai Kawasan Kesawan bagi masyarakat adalah Landmark sebesar 3(0,9\%) disusul Perlu dilestarikan sebesar $11(3,2 \%)$. 


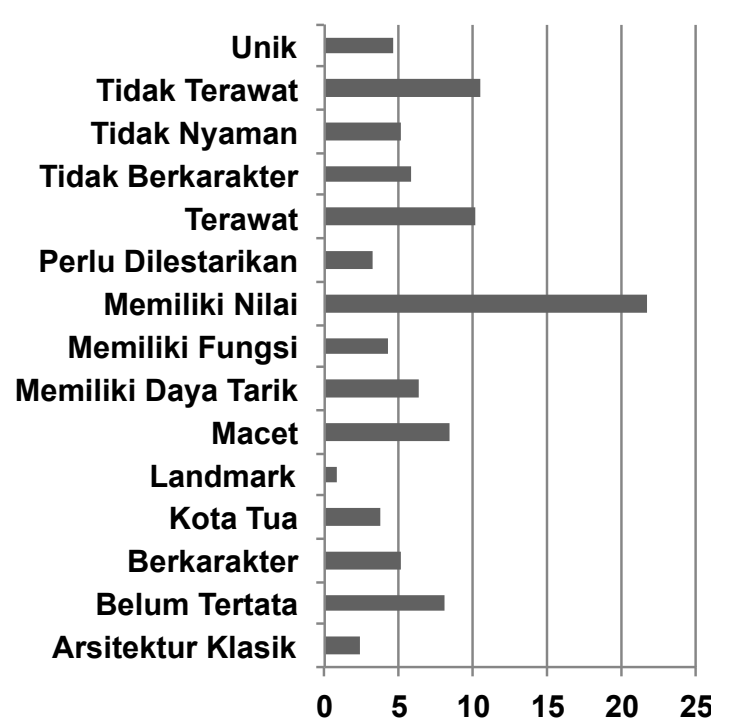

Gambar 1. Grafik. Analisis distribusi citra Kawasan Kesawan (Sumber: Analisis Pribadi, 2018)

Gambaran pemikiran masyarakat terhadap lingkungan merupakan tolak ukur dari kualitas citra kawasan. Hasil olah data dari responden menunjukkan bahwa Kawasan Kesawan masih memiliki nilai historikal. Kesawan merupakan saksi sejarah Kota Medan, namun keadaannya tidak terawat dan terbengkalai. Citra kawasan kurang dilestarikan dan tidak dianggap sebagai landmark di Kota Medan. Citra adalah gambaran mental yang terbentuk di pikiran pengamat mengenai sebuah tempat. Citra terbentuk dari hasil interaksi manusia dengan lingkungannya. Citra sangat penting untuk perkembangan sebuah kawasan terutama citra dari kawasan bersejarah (Tegar, 2017).

Citra tersebut di atas, diikuti dengan harapan terhadap Kawasan Kesawan oleh responden. Hasil analisis distribusi harapan dapat dilihat pada Grafik 2. Harapan yang paling dominan terhadap Kawasan Kesawan bagi responden, Mempertahankan bangunan lama sebesar 67(16,75\%), kemudian Tetap menjadi kawasan bersejarah sebesar 60(15\%).
Memberi vegetasi dan Memberi pengaruh terhadap lingkungan sebanyak $3(0,75 \%)$. Ini menjadi harapan yang paling sedikit disebutkan oleh responden.

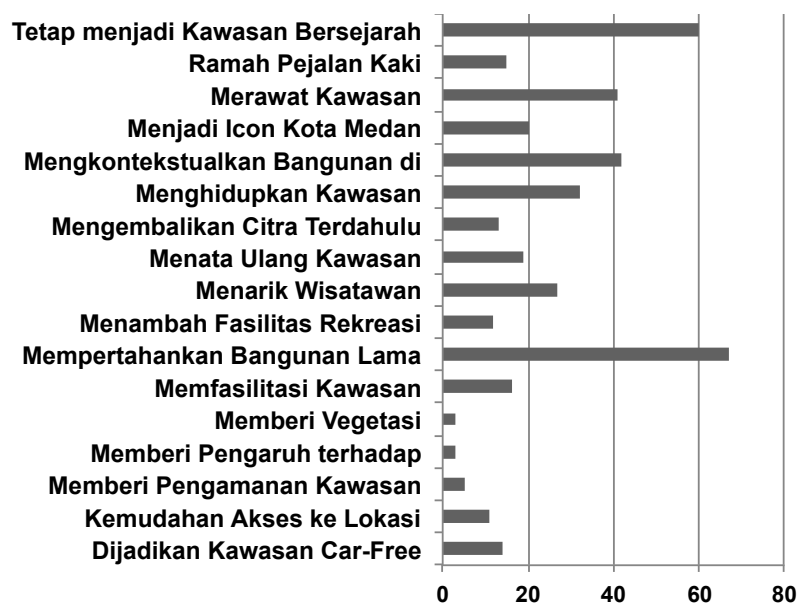

Gambar 2. Grafik. Analisis distribusi harapan Kawasan Kesawan (Sumber: Analisis Pribadi, 2018)

Dari data distribusi terlihat harapan terbesar terhadap Kawasan Kesawan dari responden adalah tetap mempertahankan bangunan lama, tetap menjadi kawasan bersejarah, bangunan dikontekstualkan dan merawat kawasan dengan baik. Untuk kelangsungan Kawasan Kesawan diharapkan tetap menampilkan kesan sejarah kedepannya.

Analisis dalam penelitian ini dilanjutkan dengan penggunaan program statistik. Analisis ini menemukan harapan yang berkaitan dengan citra yang dirasakan responden terhadap Kawasan Kesawan. Dari Gambar 1, akan terlihat bagaimana korespondensi citra dan harapan responden terhadap Kawasan Kesawan. Analisis korespondensi dilakukan dengan ward hierarchical clustering, dengan nilai signifikansi sebesar $p=0.5695$ yang menunjukkan citra dan harapan Kawasan Kesawan memiliki hubungan yang kurang signifikan.
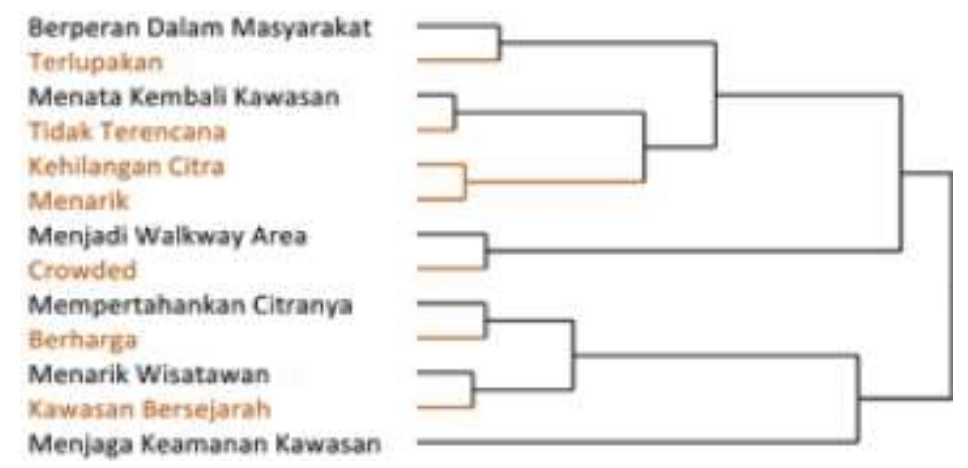

Gambar 3. Analisis korespondensi antara citra dan harapan Kawasan Kesawan $(p=0.5695)$ (Sumber: Analisis Pribadi, 2018) 


\section{HASIL DAN PEMBAHASAN}

Dari analisis korespondensi ditemukan bahwa, pendapat responden mengenai citra memiliki hubungan dengan harapan terhadap Kawasan Kesawan. Hubungan antara citra dan harapan dapat dikelompokkan menjadi enam seperti yang diuraikan di bawah ini.

\section{Kehidupan}

Permasalahan kehidupan mewakili citra terlupakan dan tidak terawat, serta harapan kawasan lebih hidup dan dimanfaatkan oleh masyarakat. Dalam Hadinugroho (2017) disampaikan bahwa tanda dari penurunan kemerosotan suatu kawasan terlihat dari kondisi pemanfaatan ruang yang terbengkalai, dengan kegiatan yang cenderung berkurang dalam waktu tertentu, dan orang tidak ingin tinggal di kawasan tersebut. Hal tersebut berdampak buruk terhadap citra kawasan. Citra ini memunculkan harapan terhadap Kawasan Kesawan. Responden mengharapkan agar Kesawan dapat berperan di tengah masyarakat. Menjadikannya sebagai lokasi event besar, dapat memberi peran di tengah lingkungan, lebih diperhatikan dan dapat menghidupkan kembali suasana yang ada di Kesawan. Keadaan Kawasan Kesawan tahun 1930 dapat dilihat pada Gambar 2 dibandingkan dengan keadaan Kawasan Kesawan yang diambil ditahun 2015 pada Gambar 3, yang diharapkan dapat berperan di tengah masyarakat sebagai lokasi event besar dan dihidupkan kembali suasananya.

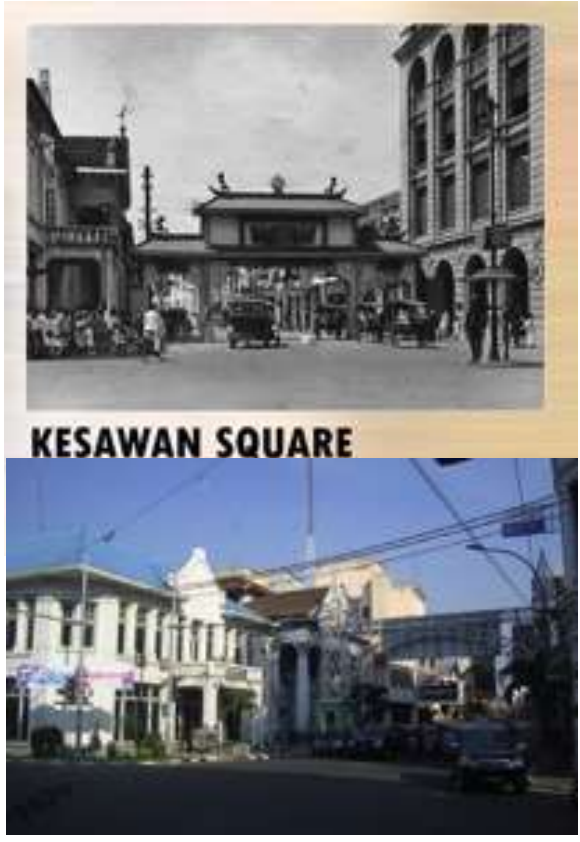

Gambar 4 (atas). Pintu masuk Kesawan dari Lapangan Merdeka tahun 1930 (Sumber: pariwisatasumut.com)

(bawah). Pintu masuk Kesawan dari Lapangan Merdeka tahun 2015

(Sumber: Dokumentasi Pribadi, 2015)

\section{Keteraturan}

Permasalahan keteraturan mewakili citra kawasan yang tidak terencana dan perlahan hilang, namun tetap memiliki daya tarik yang dan memunculkan harapan dilakukannya penataan kembali. Pendapat responden mengenai Kawasan Kesawan selanjutnya dapat diuraikan sebagai berikut. Tidak terencana yang berkaitan dengan kondisi kawasan yang kurang nyaman seperti gelap, menyeramkan, sepi, dan tidak ramah difabel.

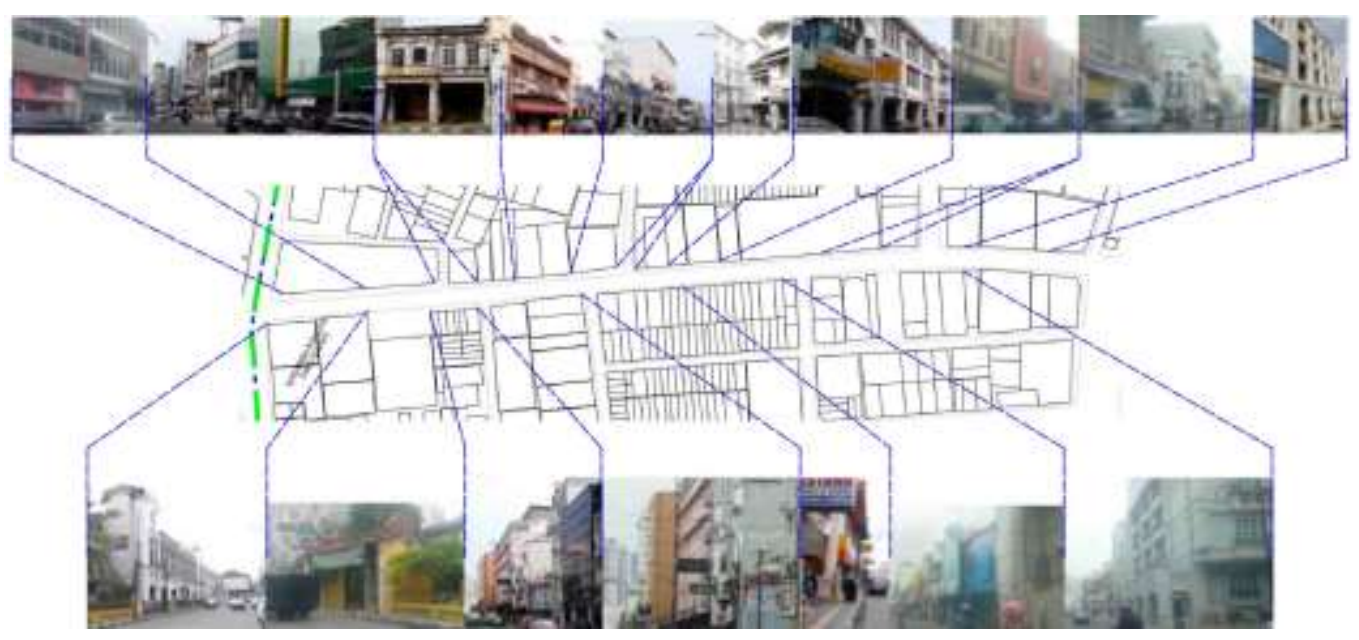

Gambar 5. Pemetaan Citra Kawasan

(Sumber: Dokumentasi Pribadi, 2018) 
Citra Kesawan saat ini dapat dilihat pada peta di Gambar 5 yang menghasilkan pendapat mengenai citra dari responden.

Pendapat responden mengenai Kawasan Kesawan berikutnya, yaitu: Kawasan Kesawan kehilangan citra. Yang dimaksud mengenai citra tersebut antara lain, kawasan tidak berkarakter dan citra terlihat biasa saja oleh responden. Ketika berada di Kawasan Kesawan, citranya menghilang, sifat bangunan kolonial juga hilang, dan tidak menarik untuk dilihat. Namun, di satu sisi citranya juga memiliki daya tarik dengan memiliki fungsi dagang dan pernah dijadikan sebagai lokasi kuliner malam hari.

Citra tersebut memunculkan harapan agar Kawasan Kesawan ditata kembali, yaitu dengan mengkontekstualkan bangunan baru dengan bangunan lama yang terlebih dahulu ada. Bentuk bangunan terdahulu memiliki cirikhas sebagai identitas dari Kesawan. Memberi vegetasi di sekitar kawasan, memiliki zona yang jelas, dan tidak berantakan juga menjadi bagian penataan kembali Kawasan Kesawan. Hal-hal ini dapat terwujud bila didukung kegiatan studi dengan kota tua seperti di Jakarta, Singapura dan tempat lain yang dianggap berhasil mewujudkan citra kawasan bersejarah.

Rencana penataan kemudian dipertimbangkan oleh para ahli tata rencana kawasan sebelum dilaksanakan. Semua rencana penataan, penambahan fasilitas dalam kawasan diharapkan tidak meninggalkan unsur kebudayaan yang ada. Kebudayaan yang sejak awal ada digabungkan dengan kebutuhan baru yang akan dimunculkan. Aspek simbolisasi yang sejalan dengan citra kawasan akan menjadi alat untuk menghidupkan kembali kawasan agar sesuai dengan kebutuhan mempertahankan sejarah namun juga menumbuhkan rasa sense of place, dan sense of belonging dalam sebuah komunitas lokal yang tinggal di kawasan bersejarah untuk ikut berkontribusi menjaga kelestarian ada di lokasi tempat tinggal mereka (Said \& Samadi, 2016).

\section{Transportasi}

Permasalahan transportasi pada Kawasan Kesawan mewakili citra crowded dan harapan dijadikan sebagai walkway area. Citra crowded yang muncul dari respon masyarakat terhadap Kesawan mewakili keadaan padat, ramai, dan macet. Ketiga hal ini berkaitan dengan harapan untuk menjadikan Kawasan
Kesawan untuk dijadikan walkway area yaitu kawasan ramah pejalan kaki, dengan membatasi akses kendaraan menuju Kesawan. Pencapaian menuju kawasan juga diharapkan agar lebih mudah diakses dengan lalu lintas yang lancar.

Untuk pedestrian dalam Peraturan Menteri Pekerjaan Umum No.30/PRT/M/2006 (Pemerintah Indonesia, 2006), sebaiknya memenuhi beberapa kriteria berikut: (1) permukaan jalan harus stabil, kuat, tahan cuaca, bertekstur halus tetapi tidak licin; (2) area istirahat; (3) pencahayaan berkisar antara 50-150 lux; (4) tepi pengaman dibuat setinggi minimum $10 \mathrm{~cm}$ dan lebar $15 \mathrm{~cm}$ sepanjang jalur pedestrian.

\section{Konservasi}

Permasalahan konservasi mewakili citra kawasan yang berharga dan harapan agar citra tetap dipertahankan. Berharganya Kesawan menurut responden berkaitan dengan adanya perpaduan budaya yang plural di dalam satu kawasan. Hal ini menjadikan Kawasaan Kesawan unik. Bentuk bangunan yang indah, kokoh, bagus, dan terawat menampilkan citra berharga bagi masyarakat. Berharga menjadikan kawasan ini perlu untuk mempertahankan citranya. Seperti yang dikatakan oleh Pawitro (2015) dengan mengetahui kekayaan dan ragam arsitektur, pengetahuan itu dapat dijadikan sebagai potensi yang telah diidentifikasi sebagai petunjuk untuk penerapan elemen dan nilai arsitektur seperti apa yang akan dipertahankan, dilestarikan di dalamnya.

Mempertahankan citra yang diharapkan oleh responden berkaitan dengan mempertahankan bangunan lama agar tetap menjadi lokasi dengan bangunan bersejarah, mengembalikan citra terdahulu, dan setelah semua dilakukan perlu adanya sikap melestarikannya, dan merawat bangunan agar menjadi lebih baik, bersih, lebih nyaman, dan memiliki sistem drainase yang lebih baik.

\section{Pariwisata}

Permasalahan pariwisata mewakili citra kawasan yang dianggap bersejarah dan harapan agar kawasan dapat menarik wisatawan. Kawasan Kesawan lekat dengan sejarah perkembangan Kota Medan. Hal ini menjadikan citra sebagai kawasan besejarah melekat pada Kesawan. Bentuk bangunan yang telah ada dari dulu hingga sekarang dan memiliki nilai sejarah seperti Restoran Tip Top 
dapat dilihat pada Gambar 6 dapat dilihat keadaannya saat ini.

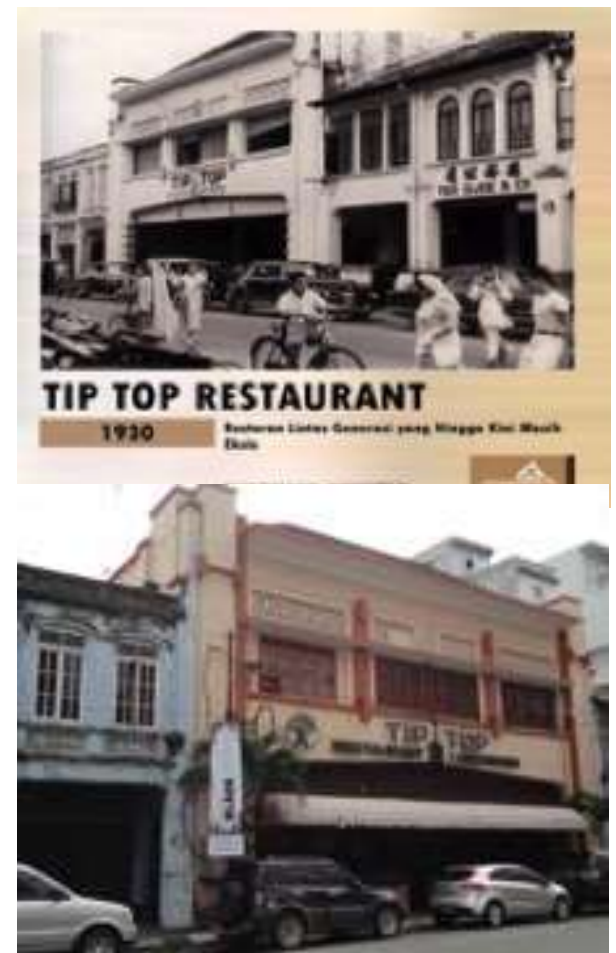

Gambar 6 (atas). Restoran lintas generasi Tip Top tahun 1930

(Sumber: pariwisatasumut.com)

(bawah). Restoran Tip Top tahun 2015

(Sumber: Dokumentasi Pribadi, 2015)

Dengan arsitektur klasik di inti kota menyebabkan masyarakat sering melewati kawasan ini. Dalam Said \& Samadi (2016) juga dijelaskan bahwa kawasan mempunyai keunikan apabila terdapat kebudayaan yang membaur satu dengan yang lain. Pernyataan ini juga mengatakan bahwa kawasan tersebut akan kaya dengan arsitektural dan gaya kebudayaan. Dalam kasus Kesawan, yaitu perpaduan kebudayaan melayu, kolonial dan cina dapat memunculkan peluang yang baik sebagai aset perkembangan ekonomi dalam kurun waktu antar generasi ke generasi karena perpaduan ini membangun sebuah kawasan yang kaya dengan kebudayaan dan ritual keagamaan dalam satu kawasan yang sama (Said \& Samadi, 2016).

Keadaan kawasan ini diharapkan dapat menarik wisatawan dengan menjadi icon Kota Medan. Memfasilitasi kawasan dengan kebutuhan pengunjung, seperti tempat parkir yang cukup, memungkinkan lokasi parkir tidak di dalam kawasan namun berdekatan dengan Kesawan, dan adanya fasilitas rekreasi sebagai wadah menuangkan kreatifitas anak muda juga diharapkan dapat menarik wisatawan untuk berkunjung.

\section{Keamanan}

Permasalahan keamanan pada kawasan menjadi pertimbangan terakhir yang perlu untuk diperhatikan. Permasalahan ini mewakili citra dan harapan dalam menjaga keamanan kawasan. Citra kawasan yang sekarang memunculkan harapan agar Kesawan lebih meningkatkan keamanan dan menghilangkan kekhawatiran ketika berada di dalam Kawasan Kesawan. Terlebih ketika berjalan di malam hari, responden mengharapkan untuk adanya kerja sama dengan pihak kepolisian untuk memantau keamanan di Kesawan. Keamanan dapat ditingkatkan dengan meletakkan kamera pemantau di sekitar kawasan. Dalam memasang pengamanan seperti CCTV perlu mempertimbangkan agar tidak mencolok karena dapat merusak visual dan kenyamanan berkurang ketika berada di lokasi (Tegar, 2017).

Berdasarkan hasil analisis korespondensi di atas ditemukan enam pola citra dan harapan terhadap Kawasan Kesawan. Enam pola tersebut dapat digambarkan dalam ilustrasi seperti di bawah ini. 


\begin{tabular}{|c|c|c|c|c|}
\hline \multirow[b]{2}{*}{1} & \multirow{2}{*}{$\begin{array}{l}\text { Permasalahan } \\
\text { Kehidupan }\end{array}$} & Citra & Terlupakan & Tidak Terawat, Kurang Tertata \\
\hline & & Harapan & $\begin{array}{l}\text { Berperan dalam } \\
\text { Masyarakat }\end{array}$ & $\begin{array}{l}\text { Menjadikan Lokasi Event Besar, Memberi peran pada lingkungan, } \\
\text { dengan Lebih diperhatikan agar Suasana kembali hidup }\end{array}$ \\
\hline \multirow{4}{*}{2} & \multirow{4}{*}{$\begin{array}{l}\text { Permasalahan } \\
\text { Keteraturan }\end{array}$} & & Tidak Terencana & Kurang nyaman : Gelap, Menyeramkan, Sepi, dan Tidak ramah difabel \\
\hline & & Citra & Kehilangan Citra & \\
\hline & & & Menarik & Memiliki fungsi dagang-kuliner malam \\
\hline & & Harapan & Ditata Kembali & $\begin{array}{l}\text { Mengkontektualkan bangunan baru dengan yang terdahulu, Memberi } \\
\text { vegetasi, Memperjelas zonasi, sehingga Tidak berantakan dengan Studi } \\
\text { preseden }\end{array}$ \\
\hline \multirow[b]{2}{*}{3} & \multirow{2}{*}{$\begin{array}{l}\text { Permasalahan } \\
\text { Transportasi }\end{array}$} & Citra & Crowded & Padat, Ramai, dan Macet \\
\hline & & Harapan & $\begin{array}{l}\text { Menjadi Walkway } \\
\text { Area }\end{array}$ & $\begin{array}{l}\text { Ramah pejalan kaki, Membatasi akses kendaraan bermotor, } \\
\text { Pencapaian lebih mudah dengan Lalu lintas yang lebih lancar }\end{array}$ \\
\hline \multirow[b]{2}{*}{4} & \multirow{2}{*}{$\begin{array}{l}\text { Permasalahan } \\
\text { Konservasi } \\
\text { (Heritage) }\end{array}$} & Citra & Berharga & $\begin{array}{l}\text { Terdapat perpaduan budaya yang plural, Unik dengan Bangunan indah } \\
\text { yang kokoh, Bagus, dan Terawat }\end{array}$ \\
\hline & & Harapan & Dipertahankan & $\begin{array}{l}\text { Tetap menjadi kawasan bersejarah, Mengembalikan citra terdahulu, } \\
\text { Melestarikannya dan Merawat bangunan agar Lebih baik, Lebih } \\
\text { nyaman dengan Perbaikan sistem drainase }\end{array}$ \\
\hline \multirow[b]{2}{*}{5} & \multirow{2}{*}{$\begin{array}{l}\text { Permasalahan } \\
\text { Pariwisata }\end{array}$} & Citra & $\begin{array}{l}\text { Kawasan } \\
\text { Bersejarah }\end{array}$ & $\begin{array}{l}\text { Lekat dengan sejarah Kota Medan, Memiliki arsitektur klasik yang } \\
\text { Berada di inti kota. }\end{array}$ \\
\hline & & Harapan & $\begin{array}{l}\text { Menarik } \\
\text { Wisatawan }\end{array}$ & $\begin{array}{l}\text { Menjadi icon Kota Medan, Memfasilitasi tempat parkir pengunjung. } \\
\text { Mewadahi kreatifitas dengan fasilitas rekreasi sebagai Penarik } \\
\text { wisatawan }\end{array}$ \\
\hline \multirow[b]{2}{*}{6} & \multirow[b]{2}{*}{$\begin{array}{l}\text { Permasalahan } \\
\text { Keamanan }\end{array}$} & & & Dari citra Kawasan Bersejarah yang Berharga \\
\hline & & Harapan & $\begin{array}{l}\text { Menjaga } \\
\text { Keamanan } \\
\text { Kawasan }\end{array}$ & $\begin{array}{l}\text { Lebih meningkatkan keamanan dengan Kerjasama dengan pihak } \\
\text { kepolisian, dan Meletakan kamera pemantau }\end{array}$ \\
\hline
\end{tabular}

Gambar 7. Enam Pola Citra dan Harapan terhadap Kawasan Kesawan (Sumber: Analisis Pribadi)

\section{KESIMPULAN}

Dari hasil analisis ditemukan enam kelompok besar hubungan antara citra dan harapan yang telah dipaparkan. Dari seluruh kelompok dapat disimpulkan bahwa citra yang paling dominan, yaitu: Kawasan Kesawan merupakan kawasan yang memiliki nilai sejarah yang menarik dengan arsitektur klasik yang unik karena perpaduan budaya kolonial, melayu, dan cina, sehingga menjadikannya kawasan dengan karakter berbeda. Potensi Kawasan Kesawan ini diharapkan dapat menjadi daya tarik bagi wisatawan. Keberadaan lokasi Kawasan Kesawan yang strategis, membuat kawasan ini dapat dijadikan kawasan kota tua juga landmark Kota Medan. Namun, sayangnya kawasan ini tidak terawat dan belum tertata. Keadaan di kawasan juga macet dan tidak nyaman untuk pejalan kaki.

Citra tersebut memunculkan harapan terhadap Kawasan Kesawan. Harapan tersebut yaitu bangunan yang telah ada sejak lama dipertahankan dan bangunan baru yang akan diperbaiki atau dibangun baru sebaiknya mengikuti bentuk bangunan lama sehingga citra yang ada di kawasan tetap terjaga keasliannya. Kawasan Kesawan juga diharapkan untuk tetap menjadi kawasan bersejarah yang menarik bagi wisatawan. Suasana yang ada di Kawasan Kesawan dapat dibuat lebih hidup dengan fasilitas area rekreasi dan area kreatifitas untuk anak muda agar dapat menuangkan ide dan kreatifitas mereka. Kawasan dijadikan sebagai lokasi event besar untuk menumbuhkan rasa sense of belonging sehingga muncul hubungan antara kawasan dan masyarakat agar tercipta peranan kawasan di tengah masyarakat. Karena kawasan tidak dapat berperan dengan sendiri tanpa adanya keterlibatan dan partisipasi masyarakat untuk menjaga kelestarian bangunan dari warisan sejarah (Virdianti et al., 2017).

Kemudahan akses ke lokasi Kawasan Kesawan juga menjadi perhatian dan harapan dari data yang telah dianalisis. Citranya yang macet memunculkan harapan untuk menjadikan Kawasan Kesawan car - free sehingga tidak boleh dilalui oleh kendaraan bermotor. Dari harapan itu muncul konsep walkway area yang ramah difabel dan pejalan kaki untuk dapat diterapkan di Kawasan Kesawan. Namun, sebelum dilakukan penerapan konsep dan penataan ulang terhadap kawasan perlu adanya studi dengan kota atau negara yang telah berhasil menerapkan konsep yang ada dengan kasus kawasan bersejarah yang sejenis dengan Kawasan Kesawan. 


\section{DAFTAR PUSTAKA}

Christyawaty, E. (2011). Rumah Tinggal Tjong a Fie: Akulturasi Dalam Arsitektur Bangunan Pada Akhir Abad Ke-19 di Kota Medan. Jurnal Sangkhakala, XIV(27), 52-70.

Cresswell, J. W. (2008). Qualitative Inquiry and Research Design_ Choosing Among Five Approaches-Sage Publications, Inc (2007).pdf (Second). California: Sage publications, inc.

Fatimah, N. B. (2017). Perencanaan Lanskap Untuk Pelestarian Kawasan Bersejarah Kesawan Medan. Institut Pertanian Bogor.

Groat, L., \& Wang, D. (2002). Qualitative research. Architectural Research Methods, pp. 173-202. New York: John Wiley \& Sons, Inc.

Hadinugroho, D. L. (2017). Kajian Model Revitalisasi Kawasan Heritage Kesawan Medan. Seminar Heritage, B045-B052. https://doi.org/10.32315/sem.1.b045

Harisdani, D. D., \& Lubis, M. D. (2004). Identitas Fungsi Ruko Kesawan. ResearchGate, 1-7.

Hutauruk, D. M., \& Rambe, Y. S. (2017). Konservasi Bangunan Tjong A Fie dalam Usaha Keberlanjutan Mempertahankan Bangunan Bersejarah Kota Medan. Journal of Architecture and Urbanism Research, 1(1), 37-44.

Ichwan, R. M. (2004). Penataan dan Revitalisasi Sebagai Upaya Meningkatkan Daya Dukung Kawasan Perkotaan. Bogor.

Pawitro, U. (2015). Preservasi-Konservasi Bangunan Bersejarah dan Pengelolaan Kawasan Kota Lama. Simposium Nasional RAPI, XIV, A13-A20.

Pemerintah Indonesia. (2006). UndangUndang No. 30 Tahun 2006 tentang Pedoman Teknis Fasilitas dan Aksesibilitas pada Bangunan Gedung dan Lingkungan. Jakarta: Menteri Pekerjaan Umum.

Pemerintah Indonesia. Undang-Undang Republik Indonesia Nomor 11 Tahun 2010 tentang Cagar Budaya. , (2010).

Said, S., \& Samadi, Z. (2016). The Evolution of Historic Streetscape in Adapting Modern Demand in Achieving the Quality of Life. Procedia - Social and Behavioral Sciences, 234, 488-497. https://doi.org/10.1016/j.sbspro.2016.10.2 67

Tegar. (2017). Pembangunan Kembali Citra Kawasan Kesawan.

Virdianti, E. ... Angkasa, D. P. (2017). Citra
Visual Koridor Kawasan Kota Lama Semarang Ditinjau Dari Potensi Wisata Edukasi Arsitektur Heritage. Jurnal Rekayasa Hijau, 1(1), 11-22. https://doi.org/10.26760/jrh.v1i1.1331 
